\title{
Suplementação e cultura de levedura na alimentação de bezerros de corte em pastagem de aveia e azevém
}

\author{
[Supplementation and yeast culture on feeding of beef calves grazing on oat and ryegrass] \\ P.E.F. Prohmann ${ }^{1}$, A.F. Branco ${ }^{1}$, C.C. Jobim $^{1}$, U. Cecato ${ }^{1}$, S. Teixeira ${ }^{1}$, W. Paris ${ }^{1}$, R.H.T.B. Goes ${ }^{2}$, \\ M.V.M. Oliveira ${ }^{2}$, F. Granzoto ${ }^{2}$ \\ ${ }^{1}$ Universidade Estadual de Maringá - Maringá, PR \\ ${ }^{2}$ Universidade Federal da Grande Dourados - Dourados, MS
}

\begin{abstract}
RESUMO
Avaliaram-se os efeitos da suplementação e o uso de cultura de levedura sobre o ganho médio diário (GMD), os parâmetros ruminais e a concentração de ureia plasmática em bezerros sob pastejo de aveia preta (Avena strigosa) e azevém (Lolium multiflorum), e estudaram-se a produção e a composição química da forragem. Utilizaram-se 32 bezerros, em pastejo contínuo e lotação variável. Os tratamentos foram: apenas mistura mineral (MM); mistura mineral mais levedura (MML); mistura mineral mais ração (MMR); e mistura mineral mais ração mais levedura (MMRL). A MM contendo casca de soja foi ofertada em 150g/animal/dia, e a levedura foi adicionada à MM na quantidade de $10 \mathrm{~g} / \mathrm{animal} / \mathrm{dia}$. A ração contendo $75 \%$ de NDT e $23 \%$ de PB foi fornecida para um consumo diário médio de $12 \mathrm{~g} / \mathrm{kg}$ de peso corporal. O GMD, para os respectivos tratamentos, foi 0,$610 ; 0,599 ; 0,809$ e $0,818 \mathrm{~kg} / \mathrm{animal}$, na ordem citada. A concentração de amônia ruminal e a de ureia plasmática não foram influenciadas pelos tratamentos. A biomassa forrageira diminuiu ao longo do ciclo vegetativo, com rendimentos inicial e final de 1.364 e $879 \mathrm{~kg}$ de $\mathrm{MS} / \mathrm{ha}$, e os teores médios de NDT e PB de 71,7 e 11,7\%, respectivamente. O fornecimento do suplemento melhorou o desempenho dos animais, e a adição de levedura não influenciou as variáveis estudadas.
\end{abstract}

Palavras-chave: aditivo, bovino, biomassa forrageira, desempenho, Sacharomices

\begin{abstract}
We evaluated the effects of supplementation and use of yeast culture on the average daily gain (ADG), ruminal parameters and plasma urea nitrogen in calves grazing oat (Avena strigosa) and ryegrass (Lolium multiflorum) and studied the production and chemical composition of forage. 32 calves were used in continuous grazing with variable stocking rate. The treatments administered were: only mineral $(M M)$, administration of mineral with yeast (MML), mineral plus ration (MMR) and mineral plus ration with yeast (MMRL). MM added with soybean hulls was supplied at $150 \mathrm{~g} /$ animal/day and yeast added to the MM in the amount of $10 \mathrm{~g} /$ animal/day. The ration containing $75 \%$ of TDN and $23 \%$ of PB was supplied for an average daily intake of $12 \mathrm{~g} / \mathrm{kg}$ of body weight. The ADG for the respective treatments were 0.610, 0.599, 0.809 and 0.818kg/animal, respectively. The concentration of ruminal ammonia and plasma urea was not affected by treatments. Forage biomasses declined throughout the growing season, with initial and final yields of 1.364 and $879 \mathrm{~kg} \mathrm{DM/ha}$, and TDN and CP levels of 71.7 and 11.7\%, respectively. The supply of the supplement improved animal performance, and the addition of yeast did not influence the variables studied.
\end{abstract}

Keywords: additive, bovine, forage biomass, performance, Saccharomyces

Recebido em 6 de outubro de 2011

Aceito em 2 de outubro de 2012

E-mail: pauloprohmann@yahoo.com.br 


\section{INTRODUÇÃO}

$\mathrm{Na}$ região Sul do Brasil, as forrageiras temperadas anuais são uma alternativa para se suprir o déficit alimentar durante a estação seca do ano. Nesse sentido, as pastagens consorciadas de aveia e azevém têm sido utilizadas com sucesso na recria de bezerros de corte, pois possuem elevado potencial forrageiro e proporcionam bons rendimentos de ganho de peso. No entanto, mesmo com essas pastagens, a maximização do rendimento por animal é limitada pela ingestão de energia (Frizzo et al., 2003a,b). Assim, o fornecimento de suplementos alimentares torna-se uma boa opção para suprir os nutrientes limitantes, melhorando o sincronismo entre energia e proteína, e podendo resultar em melhora no desempenho dos animais (Hellbrugge et al., 2008).

Todavia, o fornecimento de ração concentrada pode resultar em diminuição de consumo da forragem pelos ruminantes (Reis et al., 2009). Essa substituição pode ser desejável em determinadas ocasiões, por elevar a capacidade de suporte da área de pastoreio, sem ocasionar redução acentuada do ganho individual, melhorando, portanto, a produção animal por unidade de área (Euclides et al., 2001; Rocha et al., 2003). A opção pela suplementação depende de fatores, como a disponibilidade de forragem, a taxa de lotação e o custo do suplemento. Vale ressaltar que o conhecimento da estrutura e da composição química do pasto, bem como a verificação das mudanças quantitativas e qualitativas que as forrageiras apresentam ao longo do seu ciclo vegetativo, são fatores fundamentais para o correto balanceamento de rações que melhorem a digestibilidade $\mathrm{e}$ minimizem os efeitos sobre o consumo do pasto.

Aditivos, fornecidos junto aos grãos, que melhorem a utilização da forragem e o desempenho animal, por meio de alterações microbianas, também são desejáveis. Nesse contexto, a utilização de cultura de leveduras (Saccharomyces cerevisiae) tem sido sugerida na dieta para ruminantes (Gattas et al., 2008; Zeoula et al., 2011). As culturas de leveduras são produtos naturais que modificam a fermentação ruminal, principalmente pelo fornecimento de ácidos dicarboxílicos (ácido málico), os quais atuam como estimulantes do crescimento e do metabolismo bacteriano, e pelo consumo do oxigênio do ambiente ruminal (Goes et al., 2005).

Assim, o presente estudo foi realizado com o objetivo de avaliar o efeito da suplementação concentrada e da adição de cultura de leveduras sobre o desempenho de bezerros de corte mantidos em pastagem consorciada de aveia e azevém.

\section{MATERIAL E MÉTODOS}

O experimento foi realizado na Fazenda Dona Elisa, situada no município de Luiziana/PR, durante as estações de outono-invernoprimavera. O solo da região é o latossolo vermelho escuro (Embrapa, 1999), e o clima, segundo classificação de Koeppen, é do tipo CFA, caracterizado como subtropical úmido mesotérmico.

A pastagem consorciada de aveia preta (Avena strigosa Schreb) e azevém (Lolium multiflorum Lam) foi implantada pelo sistema de plantio direto, sobre a palhada de soja, na primeira semana de abril. No plantio, foram utilizados 105 e $40 \mathrm{~kg} / \mathrm{ha}$ de sementes de aveia e de azevém, respectivamente, bem como $125 \mathrm{~kg} / \mathrm{ha}$ do fertilizante $4 \mathrm{~N}-20 \mathrm{P}-20 \mathrm{~K}$. O pastejo dos animais iniciou 60 dias após a semeadura, quando a pastagem apresentava biomassa de forragem média de $1.364 \mathrm{~kg} /$ ha de MS. Na última semana de junho, foi realizada uma adubação de cobertura, com $30 \mathrm{~kg} / \mathrm{ha}$ de nitrogênio.

A área destinada ao experimento totalizava 8ha e foi dividida, com cerca elétrica, em quatro piquetes com tamanhos equitativos. Cada parcela continha um bebedouro e um cocho de madeira para sal, com área disponível de 0,15m/animal, e um cocho de polietileno, para distribuição de ração concentrada, com $0,5 \mathrm{~m} /$ animal e acesso por ambos os lados. Uma área contígua, com as mesmas forrageiras, foi utilizada para a manutenção dos animais reguladores e dos fistulados, que eram introduzidos na área experimental, quando necessário.

Foram utilizados 32 bezerros desmamados, com oito meses de idade e média de peso inicial de $188,7 \pm 1,85 \mathrm{~kg}$, provenientes dos grupos genéticos Red Brangus e mestiços 1/2 Red Angus com 1/2 Nelore, distribuídos aleatoriamente nos piquetes 
experimentais a fim de se uniformizar o peso e o tipo genético.

Os tratamentos testados foram: mistura mineral (MM); mistura mineral com levedura (MML); mistura mineral mais ração (MMR); e mistura mineral mais ração com levedura (MMRL). Nas Tab. 1 e 2, são apresentadas a composição dietética e a análise química dos ingredientes utilizados, respectivamente, bem como as quantidades estipuladas de consumo dos referidos suplementos. Os suplementos eram fornecidos diariamente às 13h, sendo a quantidade de suplemento ajustada de acordo com os pesos dos animais. Para se garantir a ingestão da cultura de levedura, esta foi misturada à casca de soja e ao sal mineral.

O método de pastejo adotado foi o contínuo com lotação variável, usando-se a técnica put and take (Mott e Lucas, 1952), com oito bezerros (animais testers) e um número variado de animais reguladores por tratamento, procurando se manter a massa de forragem disponível próxima a $1.200 \mathrm{~kg} / \mathrm{ha}$ de MS.

Tabela 1. Composição percentual, expressa na matéria seca, dos ingredientes das dietas mistura mineral $(\mathrm{MM})$, mistura mineral com levedura (MML), mistura mineral mais ração (MMR) e mistura mineral mais ração com levedura (MMRL)

\begin{tabular}{llcccc}
\hline Componente & MM & MML & MMR & MMRL \\
\hline \multirow{2}{*}{ Mineral } & Casca de soja & 66,7 & 60,0 & 66,7 & 66,7 \\
& Sal mineralizado & 33,3 & 33,3 & 33,3 & 33,3 \\
\hline \multirow{2}{*}{ Aditivo } & Levedura & - & 6,7 & - & 6,7 \\
& & & & & \\
\hline \multirow{5}{*}{ Ração* } & Casca de soja & - & - & 30,0 & 30,0 \\
& Farelo de algodão & - & - & 40,0 & 40,0 \\
& Milho moído & - & - & 30,0 & 30,0 \\
\hline
\end{tabular}

Consumos estimados de 150g/animal/dia, 10g/animal/dia, e de 1,2\% do peso corporal, para mineral, aditivo e ração.

* Composição da ração: NDT: 75,6\%; PB: 23,2\%; FDN: 32,9\%; FDA: 22,3\%.

A massa de forragem foi estimada conforme o método da dupla amostragem (Wilm et al., 1994) no início de cada período experimental, por meio do corte de cinco áreas delimitadas por um quadrado metálico $\left(0,25 \mathrm{~m}^{2}\right)$, cortadas rente ao solo e 10 avaliadas visualmente em cada piquete. As amostras cortadas foram individualmente pesadas e congeladas para análises posteriores.

Tabela 2. Composição química dos ingredientes utilizados nos suplementos

\begin{tabular}{lccccc}
\multirow{2}{*}{ Ingrediente } & \multirow{2}{*}{$\% \mathrm{MS}$} & \multicolumn{5}{c}{$\%$ na matéria seca } \\
\cline { 3 - 6 } & & NDT ${ }^{\mathbf{1}}$ & PB & FDN & FDA \\
\hline Casca de soja & 90,5 & 77,1 & 11,3 & 67,5 & 47,8 \\
Farelo de algodão & 88,6 & 67,7 & 43,2 & 24,8 & 17,4 \\
Milho moído & 89,4 & 84,7 & 8,5 & 9,3 & 3,4 \\
Sal mineralizado $^{*}$ & 100,0 & - & - & - & - \\
Levedura $^{*}$ & 100,0 & - & - & - & - \\
\hline
\end{tabular}

NDT estimado pela equação descrita por Undersander et al. (1993).

\#Cálcio: $110 \mathrm{~g}$; fósforo: $40 \mathrm{~g}$; sódio: $140 \mathrm{~g}$; enxofre: $8 \mathrm{~g}$; magnésio: $12 \mathrm{~g}$; manganês: $750 \mathrm{mg}$; cobalto: $45 \mathrm{mg}$; iodo: $45 \mathrm{mg}$; cobre: $825 \mathrm{mg}$; selênio: $13 \mathrm{mg}$; zinco: $2.200 \mathrm{mg}$.

*Procreatin $7^{\circledR}$ (Saf do Brasil, Produtos Alimentícios Ltda.), contendo 1 x $10^{10}$ UFC de S. cerevisiae/g de produto.

A taxa de acúmulo diário de matéria seca (TA) foi estimada utilizando-se três gaiolas de exclusão por piquete, por meio da equação proposta por Campbell (1966): $\mathrm{TA}_{\mathrm{j}}=\left(\mathrm{G}_{\mathrm{i}}-\mathrm{F}_{\mathrm{i}-}\right.$ $\left.{ }_{1}\right) / \mathrm{N}$, em que: $\mathrm{TA}_{\mathrm{j}}=$ taxa de acúmulo diário de MS no período $j$, em $\mathrm{kg} \mathrm{MS} / \mathrm{ha} / \mathrm{dia} ; \mathrm{G}_{\mathrm{i}}=\mathrm{MS}$ dentro das gaiolas no instante $i$, em $\mathrm{kg} \mathrm{MS} / \mathrm{ha}$;
$\mathrm{F}_{\mathrm{i}-1}=\mathrm{MS}$ fora das gaiolas no instante $i-1$, em $\mathrm{kg} \mathrm{MS} / \mathrm{ha} ; \mathrm{N}=$ número de dias do período $j$. A taxa de lotação (TL) por piquete foi calculada considerando-se a unidade animal (UA) como sendo $450 \mathrm{~kg}$ de peso corporal, utilizando-se a seguinte fórmula: TL = UAt /Área, em que: $\mathrm{TL}=$ taxa de lotação, em UA/ha; UAt $=$ unidade 
animal total; Área = área experimental, em ha. O cálculo da oferta de forragem foi realizado de acordo com a fórmula: $\mathrm{OF}=\mathrm{MFd}+\mathrm{TA} / \mathrm{PV}$, em que: $\mathrm{OF}=$ oferta de forragem, em $\mathrm{kg} \mathrm{MS} / \mathrm{dia} / \mathrm{kg}$ $\mathrm{PV} ; \mathrm{MFd}=$ massa de forragem diária, em $\mathrm{kg}$ MS/dia/ha; TA = taxa de acúmulo diário, em kg $\mathrm{MS} / \mathrm{dia} / \mathrm{ha} ; \mathrm{PV}=$ peso corporal dos animais, em $\mathrm{kg} / \mathrm{ha}$.

As amostras destinadas para análise da composição química do pasto foram coletadas pela técnica de esvaziamento ruminal. Para isso, foram utilizados, em substituição aos animais reguladores, quatro novilhos da raça Holandesa, providos de cânulas no rúmen, pesando em média 310kg. Antes do esvaziamento ruminal, os animais foram submetidos a jejum de sólidos de aproximadamente 14 horas, e, posteriormente, todo o conteúdo ruminal foi retirado manualmente e acondicionado em tambores de plástico. Logo em seguida, os novilhos eram conduzidos aos piquetes onde pastejavam por 30 a 40 minutos, sendo que, durante esse período, não era permitida a ingestão de água. Após o pastejo, todo o conteúdo ruminal recém-ingerido era retirado, amostrado e, em seguida, a massa ruminal, previamente acondicionada nos tambores, era recolocada no rúmen dos novilhos, e estes retornavam aos piquetes dos animais reguladores.

As amostras do conteúdo ruminal pesando, em média, $1 \mathrm{~kg}$, foram devidamente acondicionadas em sacos plásticos, congeladas e encaminhadas para as análises. Posteriormente, as amostras foram pesadas e secas em estufas com ventilação forçada de ar a $55^{\circ} \mathrm{C}$, por 72 horas, para posterior determinação do percentual de matéria seca (MS), de proteína bruta (PB), segundo a AOAC (Association..., 1990), e de fibra em detergente neutro (FDN) e fibra em detergente ácido (FDA), pelo método de partição de fibras (Van Soest et $a l ., 1991)$. Os valores referentes aos nutrientes digestíveis totais (NDT) foram estimados por meio da equação proposta por Undersander et al. (1993), \% NDT = 105,2 - (0,667 x FDN $)$.

A determinação da concentração de ureia plasmática foi efetuada em amostras de sangue coletadas na jugular dos animais, duas horas após o fornecimento do suplemento. As coletas foram realizadas no período da tarde, em tronco de contenção, sempre um dia antes das pesagens, na ocasião em que os animais eram conduzidos até o centro de manejo para permanecerem em jejum. As amostras de sangue foram coletadas em tubos contendo heparina, refrigeradas e imediatamente encaminhadas para análise, sendo, então, centrifugadas a $3000 \times$ g por 15 minutos, à temperatura de $4^{\circ} \mathrm{C}$, seguindo-se remoção e congelamento do plasma. Posteriormente, após o descongelamento, efetuado em temperatura ambiente, as amostras foram submetidas às análises de ureia plasmática, pelo método enzimático (urease/glutamato desidrogenase), segundo Talke e Schubert (1965), usando-se um analisador automático.

Os animais fistulados também foram utilizados para se determinar o $\mathrm{pH}$ e a concentração de amônia ruminal $\left(\mathrm{N}-\mathrm{NH}_{3}\right)$. Assim, durante 14 dias de cada período de pastoreio, em substituição aos animais reguladores, eles eram alocados nos piquetes pastejados pelos bezerros e suplementados com os mesmos tratamentos.

As coletas de líquido ruminal foram realizadas no $14^{\circ}$ dia, antes do fornecimento do suplemento e às duas, quatro e seis horas após. Coletaram-se aproximadamente $100 \mathrm{~mL}$ de líquido via cânula ruminal, da interface sólido/líquido do rúmen, o qual foi dividido em duas alíquotas de $50 \mathrm{~mL}$. Uma amostra foi usada para a determinação do $\mathrm{pH}$, realizada logo após a coleta, utilizando-se um peagâmetro digital. A outra alíquota foi acondicionada em recipientes plásticos, conservada com $1 \mathrm{~mL}$ de solução de $\mathrm{H}_{2} \mathrm{SO}_{4}$, na proporção de 1:1, e armazenada a $-10^{\circ} \mathrm{C}$. Posteriormente o líquido ruminal foi descongelado em temperatura ambiente e centrifugado a 3000 x $g$ por 15 minutos. A análise do $\mathrm{N}$ amoniacal $\left(\mathrm{N}-\mathrm{NH}_{3}\right)$ no fluido sobrenadante foi realizada por meio de titulação com $\mathrm{KOH}$ a $2 \mathrm{~N}$, com posterior retenção em solução de ácido bórico e titulação com $\mathrm{HCl}$ a $0,005 \mathrm{~N}$

O ganho de peso individual dos animais testers foi determinado por pesagem em intervalos de 28 dias, no período da manhã, após jejum de sólidos e líquidos de aproximadamente 14 horas. O ganho de peso por hectare (GPA) foi obtido multiplicando-se o número de animais/dia/ha pelo ganho de peso médio diário (GMD) dos animais testers, multiplicado pelo número de dias de cada período. 
O delineamento utilizado foi o inteiramente ao acaso e os dados das variáveis estudadas foram submetidos à análise de variância. Em relação às análises de $\mathrm{pH}$ e amônia ruminal, acrescentou-se ao modelo a variável $\mathrm{A}_{\mathrm{j}}=$ efeito do indivíduo $j$, com $j$ variando de 1 a 4 . Para comparação entre médias, foi utilizado o teste Tukey a $5 \%$ de probabilidade, com uso do programa SAEG (Sistemas..., 2007).
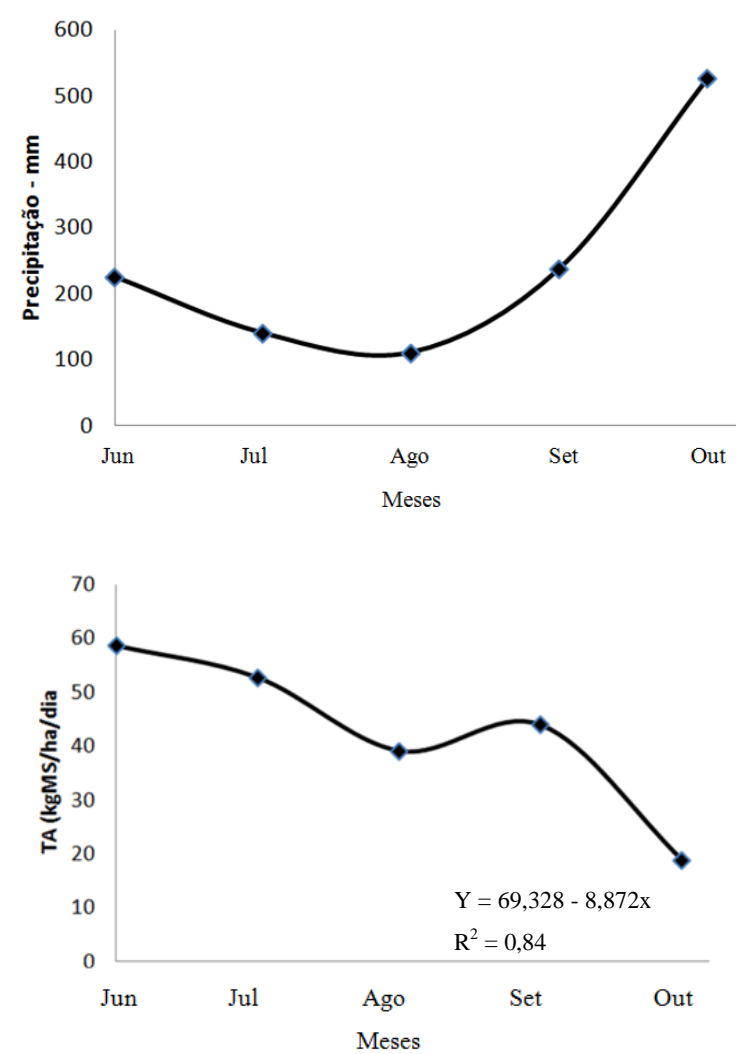

\section{RESULTADOS E DISCUSSÃO}

Foi observado efeito linear $(\mathrm{P}<0,05)$ em função do estádio vegetativo das gramíneas. Ao longo das avaliações, ocorreu redução da biomassa de forragem (BF) e da taxa de acúmulo diário (TA) de MS. Houve aumento da oferta de forragem (OF) para os animais mantidos em pastoreio, possivelmente em razão de se aplicar uma taxa de lotação variável, mediante uso da técnica put and take (Fig. 1).
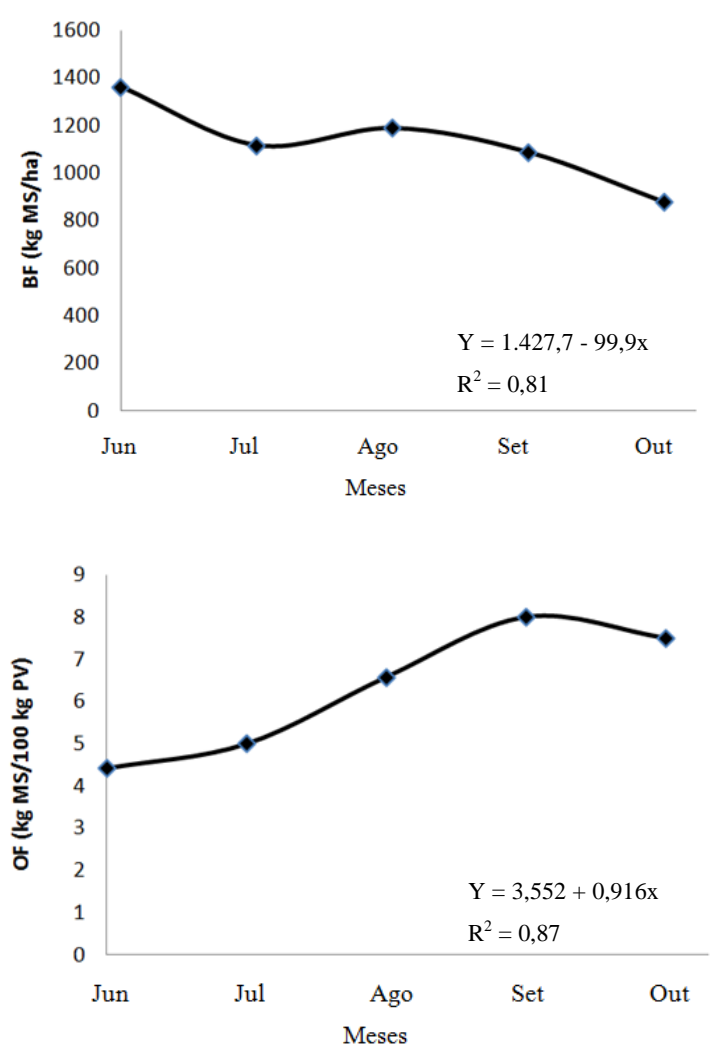

Figura 1. Precipitação e valores da biomassa de forragem (BF), da taxa de acúmulo diário (TA) e da oferta de forragem (OF) em pastagem consorciada de aveia e azevém, pastoreada por novilhos de corte (média dos tratamentos).

Segundo Pilau et al. (2005), a disponibilidade de biomassa forrageira para gramíneas temperadas de aveia consorciada com azevém deve ser ao redor de $1200 \mathrm{~kg}$ de $\mathrm{MS} / \mathrm{ha}$, para que ocorra uma melhor eficiência de colheita de forragem pelo animal, sem limitar a seletividade e, consequentemente, o desempenho. Neste trabalho, a biomassa média foi de $1.128 \mathrm{~kg}$ MS/ha, valor próximo, portanto, ao sugerido.
Observou-se diferença $(\mathrm{P}<0,05)$ entre os teores de MS, PB, NDT, FDN e FDA do pasto (Tab. 4), entre os períodos de pastejo. O teor de MS do pasto elevou-se em função do estádio vegetativo das gramíneas, com aumento de $0,04 \%$ para cada dia de pastoreio. A redução observada no mês de agosto foi explicada pelo processo de maturação fisiológica mais tardio do azevém em relação à aveia. Frizzo et al. (2003b), ao trabalharem com animais suplementados com concentrado energético, em pastagens consorciadas de aveia e 
azevém, verificaram aumento de $0,02 \%$ no teor de MS, para cada dia de pastejo.

Os valores de NDT e PB apresentaram comportamento linear inverso, com redução de $0,03 \%$ para cada dia de pastejo. Tal,comportamento está de acordo com o avanço da maturação das plantas, que proporcionou aumento na concentração de FDN e FDA, com reduções de 0,03 e $0,02 \%$ para cada dia pastoreado. Frizzo et al. (2003b) encontraram na pastagem consorciada de aveia e azevém decréscimo de $0,07 \%$ no teor de $\mathrm{PB}$, devido à aproximação do fim do ciclo de produção das espécies, com consequente aumento da quantidade de colmos, com menor teor de nitrogênio, em relação a folhas.

Tabela 4. Teores de matéria seca (MS), nutrientes digestíveis totais (NDT), proteína bruta (PB), fibra em detergente neutro (FDN) e fibra em detergente ácido (FDA) do pasto de aveia e azevém ingeridas pelos animais

\begin{tabular}{lccccc}
\hline \multirow{2}{*}{ Mês } & $\%$ MS & \multicolumn{4}{c}{$\%$ na matéria seca } \\
\cline { 3 - 5 } & & NDT & PB & FDN & FDA \\
\hline Junho & $16,4 \mathrm{~d}$ & $76,4^{\mathrm{a}}$ & $13,3 \mathrm{a}$ & $43,2 \mathrm{c}$ & $22,9 \mathrm{~b}$ \\
Julho & $22,5 \mathrm{c}$ & $74,3^{\mathrm{a}}$ & $12,8 \mathrm{a}$ & $46,3 \mathrm{c}$ & $24,5 \mathrm{~b}$ \\
Agosto & $18,0 \mathrm{~d}$ & $70,2 \mathrm{ab}$ & $12,3 \mathrm{ab}$ & $52,4 \mathrm{~b}$ & $24,3 \mathrm{~b}$ \\
Setembro & $28,5 \mathrm{~b}$ & $65,7 \mathrm{~b}$ & $11,8 \mathrm{ab}$ & $59,2 \mathrm{a}$ & $30,2 \mathrm{a}$ \\
Outubro & $57,6 \mathrm{a}$ & $68,4 \mathrm{~b}$ & $10,6 \mathrm{ab}$ & $55,2 \mathrm{ab}$ & $24,2 \mathrm{~b}$ \\
\hline Média & 28,4 & 71,7 & 11,7 & 50,2 & 25,1 \\
\hline
\end{tabular}

Médias seguidas de letras distintas na coluna diferem estatisticamente pelo teste de Tukey $(\mathrm{P}<0,05)$

NDT estimado por meio da equação descrita por Undersander et al. (1993).

O ganho de peso dos animais acompanhou a curva de crescimento da pastagem; assim, observou-se maior GMD nos períodos iniciais de pastejo em função da melhor qualidade do pasto (Fig. 2). De acordo com Frizzo et al. (2003a), a queda no desempenho de animais mantidos em pastagens de inverno ocorre principalmente pela limitação da ingestão de energia e em consequência do término do ciclo vegetativo das forrageiras temperadas anuais.

Nos animais suplementados com ração concentrada, os ganhos de pesos foram $35 \%$ mais altos em relação aos ganhos de bezerros que receberam a mistura mineral (Tab. 5). Segundo Hellbrugge et al. (2008), a melhora no desempenho em animais suplementados ocorre pelo maior aporte e sincronia de energia e proteína, o que supre a deficiência nutricional do pasto.

Neste ensaio, o ganho de peso dos bezerros que receberam apenas mistura mineral e o dos suplementados com $1,2 \%$ do peso vivo com ração concentrada foram de 0,605 e $0,814 \mathrm{~kg} / \mathrm{dia}$, respectivamente. De maneira semelhante, Frizzo et al. (2003a) encontraram, para novilhos Charolês que receberam $1,4 \%$ do peso vivo de suplementação energética, ganhos de $0,844 \mathrm{~kg} / \mathrm{dia}$. Hellbrugge et al. (2008), ao trabalharem com pastagem consorciada de aveia e azevém, encontraram ganhos diários de $1,680 \mathrm{~kg}$ para animais suplementados com $0,4 \%$ do peso vivo com grãos de milho, e $1,360 \mathrm{~kg} /$ dia para os não suplementados.

Neste ensaio, os maiores ganhos para MMR e MMRL provavelmente ocorreram em razão da substituição da forragem pelo suplemento, devido à quantidade fornecida $(12 \mathrm{~g} / \mathrm{kg}$ de peso vivo), o que permitiu maior aporte energético e proteico em função da concentração de nutrientes no suplemento. Fieser e Vanzant (2004) demonstraram que a suplementação pode aumentar o consumo total de matéria orgânica (MO), mesmo com o efeito de substituição, o que poderá ocasionar maiores desempenhos. 

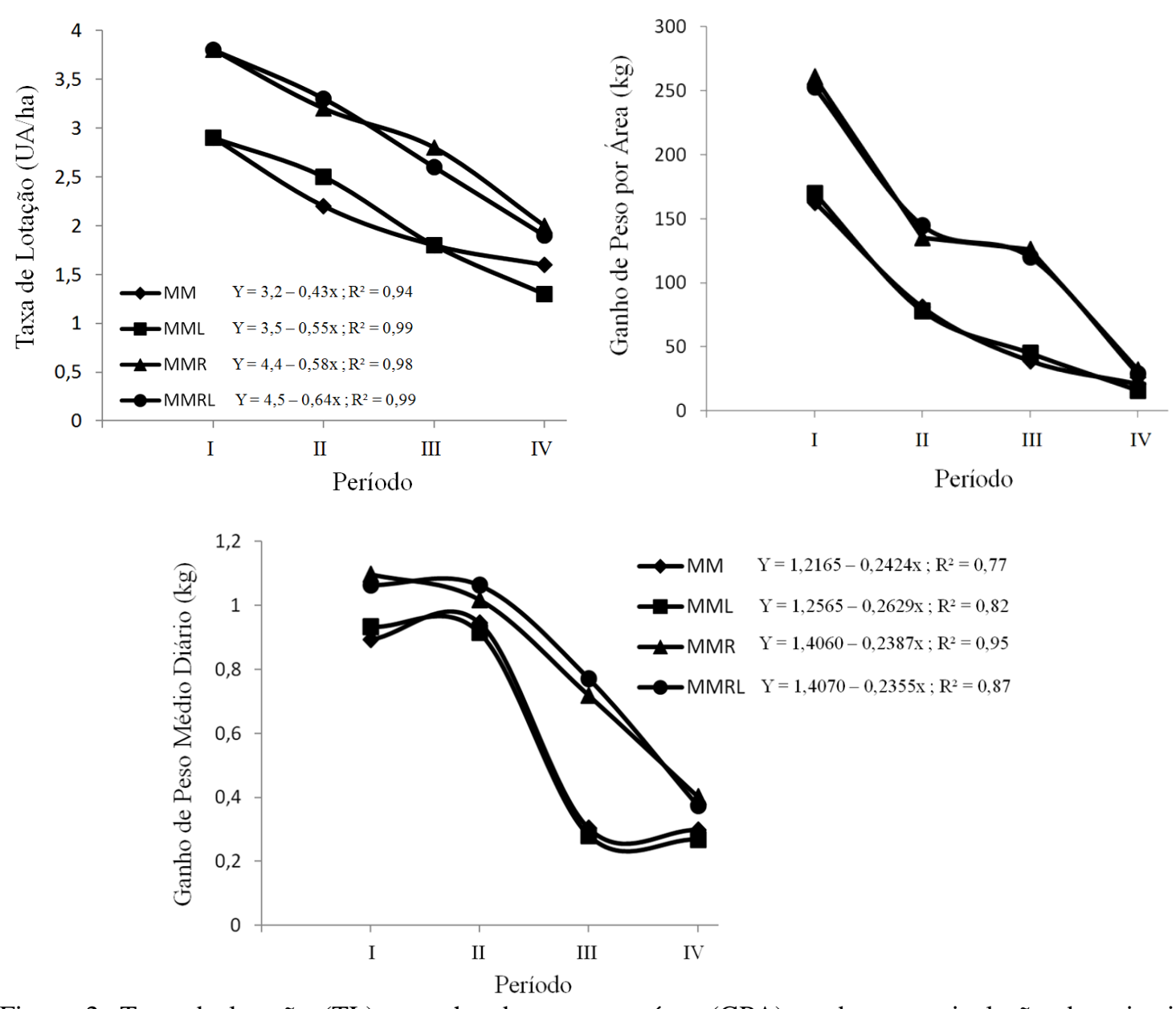

Figura 2. Taxa de lotação (TL) e ganho de peso por área (GPA), ambos com inclusão de animais reguladores, e ganho de peso médio diário (GMD) dos animais testers, por período (junho a outubro), em pastagem de aveia e azevém com suplementação de mistura mineral (MM), mistura mineral com levedura (MML), mistura mineral mais ração (MMR) e mistura mineral mais ração com levedura (MMRL).

Tabela 5. Peso corporal (PC) inicial e final e ganhos de peso médios diários (GMD) e totais (GPT) e ureia plasmática, com seus respectivos erros-padrão da média de bezerros em pasto de aveia e azevém, suplementados com mistura mineral (MM), mistura mineral com levedura (MML), mistura mineral mais ração (MMR) e mistura mineral mais ração com levedura (MMRL)

\begin{tabular}{lccccc} 
Tratamento & $\begin{array}{c}\text { PV inicial } \\
(\mathrm{kg})\end{array}$ & $\begin{array}{c}\text { PV final } \\
(\mathrm{kg})\end{array}$ & $\begin{array}{c}\text { GMD } \\
(\mathrm{kg} / \mathrm{dia})\end{array}$ & $\begin{array}{c}\text { GPT } \\
(\mathrm{kg} / \mathrm{ha})\end{array}$ & Ureia plasmática \\
\hline MM & 186,8 & 255,1 & $0,610 \mathrm{~b} \pm 0,06$ & $68,32 \mathrm{~b} \pm 0,06$ & $22,9 \mathrm{a} \pm 0,57$ \\
MML & 191,1 & 258,2 & $0,599 \mathrm{~b} \pm 0,07$ & $67,09 \mathrm{~b} \pm 0,07$ & $24,8 \mathrm{a} \pm 0,71$ \\
MMR & 187,0 & 277,6 & $0,809 \mathrm{a} \pm 0,06$ & $90,61 \mathrm{a} \pm 0,06$ & $24,8 \mathrm{a} \pm 0,59$ \\
MMRL & 189,9 & 281,5 & $0,818 \mathrm{a} \pm 0,06$ & $91,62 \mathrm{a} \pm 0,06$ & $23,6 \mathrm{a} \pm 1,05$ \\
\hline
\end{tabular}

Médias seguidas de letras distintas na coluna diferem estatisticamente pelo teste de Tukey $(\mathrm{P}<0,05)$.

Segundo o NRC (National..., 2000), as exigências nutricionais de bezerros de corte com $234 \mathrm{~kg}$, peso vivo médio deste trabalho, para ganhos de $0,800 \mathrm{~kg} / \mathrm{dia}$, são de $6,8 \mathrm{~kg}$ para MS, $115 \mathrm{~g} / \mathrm{kg}$ para PB e $602 \mathrm{~g} / \mathrm{kg}$ para NDT. Assim, neste experimento, o conteúdo energético e proteico do pasto consorciado de aveia e azevém, durante o seu ciclo vegetativo, foi suficiente para suprir as exigências dos animais. Verificou-se, todavia, que à medida que o ciclo vegetativo avançou e a planta se desenvolveu, ocorreu redução do teor de $\mathrm{PB}$ disponível na pastagem. 
No entanto, o fornecimento de mistura mineral e de ração concentrada proporcionou melhora na qualidade da dieta, disponibilizando $72,7 \mathrm{~g} / \mathrm{kg}$ e $232 \mathrm{~g} / \mathrm{kg}$ de $\mathrm{PB}$, respectivamente, mantendo, assim, o crescimento dos animais de maneira satisfatória.

Em relação ao ganho de peso total (GPT), os animais suplementados ganharam, em média, $23 \mathrm{~kg}$ de peso a mais, se comparados aos animais não suplementados (Tab. 5). Hellbrugge et al. (2008) encontraram ganhos de $16,8 \mathrm{~kg}$ a mais por animal suplementado, porém com uma ingestão média de $4 \mathrm{~g} / \mathrm{kg}$ de peso vivo de milho.

Quanto ao fornecimento da cultura de levedura, não foi verificada influência $(\mathrm{P}<0,05)$ no desempenho dos animais. O ganho dos bezerros que receberam a cultura de levedura associada ao suplemento foi apenas 1,1\% superior em relação aos que não receberam levedura.

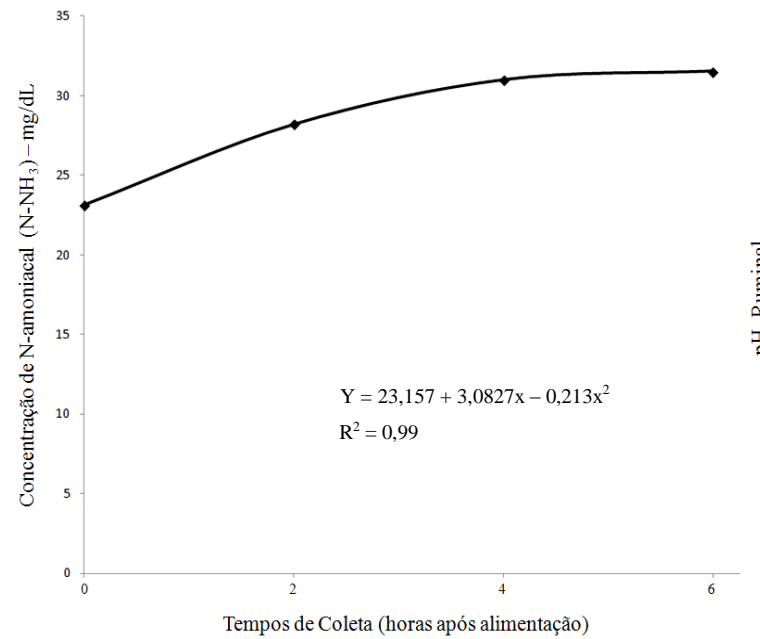

Em termos de ambiente ruminal, o maior $\mathrm{pH}$ $(6,31)$ foi observado nos animais que receberam mistura mineral, mas não se observou influência da levedura sobre esta variável, com média de 6,13 (Fig. 3). Os animais que receberam MMR apresentaram $\mathrm{pH}$ médio, de 5,95, abaixo do valor proposto por Owens e Goetsch (1988), de 6,0, como sendo limitante para a degradação da fibra. Esse menor valor de $\mathrm{pH}$ pode estar associado à presença de carboidratos de rápida fermentação, que podem ocasionar alterações na microbiota ruminal (Van Soest, 1994). Simeone et al. (2004), ao suplementarem novilhos com milho inteiro ou moído para novilhos, na quantidade de $1,0 \%$ do peso vivo, em pastagens de azevém, não observaram diferenças no $\mathrm{pH}$ ruminal entre animais suplementados ou não, com média de 6,05

Figura 3. Concentração de $\mathrm{N}$-amoniacal e pH no líquido ruminal de bovinos mantidos em pastagem de aveia e azevém, suplementados com mistura mineral (MM), mistura mineral com levedura (MML), mistura mineral mais ração (MMR) e mistura mineral mais ração com levedura (MMRL).

A inclusão de cultura de levedura para os animais suplementados com ração proporcionou elevação nos valores de $\mathrm{pH}$, com média de 6,11 , o que demonstrou a capacidade desse probiótico em estabilizar o ambiente ruminal quando elevadas quantidades de concentrado são incorporadas à dieta. Todavia, Gattas et al. (2008), ao fornecerem levedura na quantidade de $1 \mathrm{~g} / 100 \mathrm{~kg}$ de peso vivo para bovinos de corte, não encontraram alterações no $\mathrm{pH}$ ruminal. De maneira semelhante, Zeoula et al. (2011) também não observaram, em bovinos Holandeses, com
$518 \mathrm{~kg}$ e suplementados diariamente com $5 \mathrm{~g}$ de levedura por animal, efeito da levedura sobre o pH ruminal, com média de 6,4 .

Neste ensaio, também não foram observadas diferenças $(\mathrm{P}>0,05)$ na concentração de amônia ruminal entre os tratamentos e nem na interação entre tratamentos e tempo de coleta. Entretanto, houve efeito significativo do tempo de coleta, sendo, portanto, os dados ajustados numa única equação de regressão (Fig. 3). Neste caso, o ponto máximo estimado da concentração de N- 
$\mathrm{NH}_{3}$ foi de $31,6 \mathrm{mg} / \mathrm{dL}$, e ocorreu cinco horas e meia após o fornecimento do suplemento. A adição da cultura de levedura também não proporcionou efeito na concentração de Namoniacal, resultado que corrobora os de Gattas et al. (2008) e Zeoula et al. (2011), os quais também não observaram mudanças no $\mathrm{N}-\mathrm{NH}_{3}$ ruminal, com médias de 8,81 e $12,5 \mathrm{mg} / \mathrm{dL}$, respectivamente.

Neste experimento, o maior ganho de peso por área (GPA) foi observado no primeiro período de pastejo, havendo sequencialmente uma diminuição do ganho devido à menor disponibilidade de biomassa e da piora da qualidade nutritiva do pasto, em função do avanço do ciclo vegetativo das gramíneas. Verificou-se, ainda, nos animais suplementados com ração concentrada, aumento de $79,6 \%$ no GPA em comparação aos bezerros que consumiram mistura mineral. No entanto, para cada quilo de ganho de peso adicional por hectare, em relação ao tratamento $\mathrm{MM}$, foram consumidos 7,3 e 7,5kg de suplemento para os tratamentos MMR e MMRL, respectivamente.

De maneira semelhante, Rocha et al. (2003) também observaram reduções expressivas no ganho de peso de bovinos entre o início e o final do ciclo de maturação, das forrageiras aveia preta e azevém. Segundo esses autores, os animais suplementados com 1,5\% do peso vivo com grãos de sorgo triturado apresentaram um GPA $75 \%$ superior aos animais não suplementados, havendo um consumo de $7,4 \mathrm{~kg}$ de grãos de sorgo para cada quilo de ganho por hectare.

Em relação à taxa de lotação, foi observada uma diminuição linear com o avanço do estádio vegetativo das gramíneas, havendo uma redução de $45 \%$ no número de unidade de animal por hectare (UA/ha). Todavia, a área em que foram mantidos os animais suplementados com ração concentrada permitiu um aumento de $27,6 \%$ no número de UA/ha (Fig. 2). Frizzo et al. (2003a) também destacaram que a suplementação energética apresenta efeito aditivo e substitutivo em pastagem cultivada de inverno de aveia e azevém, aumentando a carga animal, porém os maiores efeitos estão relacionados com o ciclo das forrageiras.
Neste experimento, os diferentes tratamentos proporcionaram valores de $\mathrm{N}$-ureico plasmático (NUP) semelhantes $(\mathrm{P}>0,05)$, com média de 24mg/dL (Tab. 5), e, portanto, dentro dos limites considerados normais para bovinos, de 10 a 30mg/dL (Swenson e Reece, 1996). Verificou-se, assim, que, apesar de os tratamentos MMR e MMRL proporcionarem maior aporte proteico para os animais, este não foi suficiente para alterar os valores de NUP. Lanna et al. (1998) afirmaram que as variações nos valores de NUP estão associadas à maior deposição de proteína e com a maior disponibilidade de substratos fermentescíveis no rúmen. Desse modo, segundo Oliveira et al. (2001), aumentos na concentração de NUP geralmente são observados quando ocorrem aumentos da concentração de amônia ruminal, em razão da menor eficiência de utilização desse composto. Nesse sentido, Huntington et al. (2001) também afirmaram que aumentos na concentração de NUP estão relacionados com a elevação nos teores de PB da dieta.

Neste trabalho, a adição de cultura de levedura também não produziu modificações nas concentrações de NUP, tanto para animais suplementados com ração quanto para aqueles que receberam apenas mistura mineral.

\section{CONCLUSÕES}

A suplementação de $1,2 \%$ do peso vivo com ração concentrada a bezerros de corte mantidos em pastagens consorciadas de aveia e azevém reduziu o $\mathrm{pH}$ ruminal, melhorou o ganho de peso diário, elevou a taxa de lotação e o ganho de peso por área, sem alterar a concentração do N$\mathrm{NH}_{3}$ ruminal e o $\mathrm{N}$-ureico plasmático. A adição de cultura de levedura não influenciou nenhuma variável analisada, com exceção do $\mathrm{pH}$ ruminal, mais elevado nos animais suplementados com ração.

\section{AGRADECIMENTOS}

Ao Conselho Nacional de Pesquisa e Desenvolvimento Científico e Tecnológico $\mathrm{CNPq}$, pelo apoio financeiro a este trabalho. 


\section{REFERÊNCIAS}

ASSOCIATION of official analytical chemists AOAC. Official methods of analysis. 15.ed. Arlington: 1990. 1298p.

CAMPBELL, A.G. Grazed pastures parameters: I. Pasture dry-matter production and availability in a stocking rate and grazing management experiment with dairy cows. J. Agric. Sci., v.67, p.211-216, 1966.

EMBRAPA - Empresa Brasileira de Pesquisa Agropecuária. Sistema Brasileiro de Classificação dos Solos. Brasília: Embrapa, 1999. 412p.

EUCLIDES, V.P.B.; EUCLIDES FILHO, K.; COSTA, F.P. et al., Desempenho de novilhos F1 Angus-Nelore em pastagens de Brachiaria decumbens submetidos a diferentes regimes alimentares. Rev. Bras. Zootec., v.30, p.470-481, 2001.

FIESER, B.G.; VANZANT, E.S. Interactions between supplement energy source and tall fescue hay maturity on forage utilization by beef steers. J. Anim. Sci., v.82, p.307-318, 2004.

FRIZZO, A.; ROCHA, M.G.; RESTLE, J. et al. Suplementação energética na recria de bezerras de corte mantidas em pastagem de inverno. Rev. Bras. Zootec., v.32, p.643-652, 2003 a.

FRIZZO, A.; ROCHA, M.G.; RESTLE, J. et al. Produção de forragem e retorno econômico da pastagem de aveia e azevém sob pastejo com bezerras de corte submetidas a níveis de suplementação energética. Rev. Bras. Zootec., v.32, p.632-642, 2003b.

GATTAS, C.B.A.; MORAIS, M.G.; ABREU, U.G.P. et al. Efeito da suplementação com cultura de levedura na fermentação ruminal de bovinos de corte. Rev. Bras. Zootec., v.37, p.711716,2008

GOES, R.H.T.B.; ALVES, D.D.; VALADARES FILHO, S.C. et al. Utilização de aditivos alimentares microbianos na alimentação de bovinos de corte e leite: Revisão. Arq. Cienc. Vet. Zool. Unipar, v.8, p.47-56, 2005.
HELLBRUGGE, C.; MOREIRA, F.B.; MIZUBUTI, I.Y. et al. Desempenho de bovinos de corte em pastagem de azevém (Lolium Multiflorum) com ou sem suplementação energética. Semina: Cienc. Agr., v.29, p.723-730, 2008.

HUNTINGTON, G.; POORE, M.; HOPKINS, B. et al. Effect of ruminal protein degradability on growth and $\mathrm{N}$ metabolism in growing beef steers. J. Anim. Sci., v.79, p.533-541, 2001.

LANNA, D.P.D.; MORAIS, J.P.; BOIN, C. et al. Desempenho e composição corporal de novilhas alimentadas com dois níveis de concentrado e bagaço de cana submetidos a diferentes processos de hidrólise. Rev. Bras. Zootec., v.28, p.412-420, 1998.

MOTT, G.O.; LUCAS, H.L. The design, conduct and interpretation of grazing trials on cultivated and improved pastures. In: INTERNATIONAL GRASSLAND CONGRESS, 1952, Pensylvania. Proceedings... Pensylvania: State College Press, p.1385. 1952.

NATIONAL Research Council - NRC. Nutrient Requirements of Beef Cattle. 7th ed. Washington D.C., 2000. 233p.

OLIVEIRA, A.S.; VALADARES, R.F.D.; VALADARES FILHO, S.C. et al. Produção de proteína microbiana e estimativas das excreções de derivados de purinas e de ureia em vacas lactantes alimentadas com rações contendo diferentes níveis de compostos nitrogenados nãoproteicos. Rev. Bras. Zootec., v.30, p.1621-1629, 2001.

OWENS, F.N.; GOETSCH, A.L. Ruminal fermentation. In: CHURCH, D.C. (Ed.). The Ruminant Animal: Digestive, Physiology and Nutrition. Englewood Cliffs: Simon e Schuster, p.145-171, 1988.

PILAU, A.; ROCHA, M.G.; RESTLE, J. et al. Desenvolvimento de novilhas de corte recebendo ou não suplementação energética em pastagens com diferentes disponibilidades de forragem. Rev. Bras. Zootec., v.34, p.1483-1492, 2005.

REIS, R.A.; RUGGIERI, A.C.; CASAGRANDE, D.R. et al. Suplementação da dieta de bovinos de corte como estratégia do manejo das pastagens. Rev. Bras. Zootec., v.38, p.147-159, 2009. 
ROCHA, M.G.; RESTLE, J.; PILAU, A. et al. Produção animal e retorno econômico da suplementação em pastagem de aveia preta e azevém. Cienc. Rural, v.33, p.85-93, 2003.

SIMEONE, A.; BERETTA, V.; ROWE, J. et al. Rumen fermentation in Hereford steers grazing rygrass and supplement with whole or ground maize. Anim. Prod. Austr., v.25, p.168-171, 2004.

SISTEMAS de Análises Estatísticas e Genéticas (Versão 9.0) Manual do Usuário. UNIVERSIDADE FEDERAL DE VIÇOSA (UFV). S.A.E.G. Viçosa, MG, 2007. 91p.

SWENSON, M.J.; REECE, W.O. Dukes Fisiologia dos Animais Domésticos. Guanabara Koogan: Rio de Janeiro. 11.ed, 1996. 856p.

TALKE, H.; SCHUBERT, G.E. Enzymatische harnstoffb estimmung in blut und serum im optischen test nach warburg. Klinical Wochenschr, v.43, p.174-175, 1965.
UNDERSANDER, D; MERTENS, D.R.; THIEX, N. Forage Analysis Procedures, 1993.139p.

Van SOEST, P.J.; ROBERTSON, J.B.; LEWIS, B.A. Methods for dietary fiber, and nonstarch polysaccharides in relation to animal nutrition. $J$. Dairy Sci., v.74, p.3583-3597, 1991.

Van SOEST, P.J. Nutritional Ecology of the Ruminant. 2.ed. Ithaca: Cornell University Press, 1994. 476p.

WILM, H.G.; COSTELO, O.F.; KLIPPLE, G.E. Estimating forage yield by the double sampling method. J. Amer. Soc. Agr., v.36, p.194-203, 1994.

ZEOULA, L.M.; BELEZE, J.R.F.; MAEDA, E.M. et al. Levedura ou monensina na dieta de bovinos e bubalinos sobre a fermentação ruminal e eficiência microbiana. Acta Sci. Ani. Sci., v.33, p.379-386, 2011. 